\title{
Aortic Valve Disorder
}

National Cancer Institute

\section{Source}

National Cancer Institute. Aortic Valve Disorder. NCI Thesaurus. Code C78650.

A heart disorder characterized by a defect in aortic valve structure or function. 